\title{
Risk Assessment for Metals and PAHs by Mediterranean Seafood
}

\author{
Chiara Copat $^{1}$, Gea Oliveri Conti ${ }^{*}$, Carlo Signorelli ${ }^{2}$, Sandra Marmiroli ${ }^{3}$, Salvatore Sciacca ${ }^{1}$, \\ Marco Vinceti ${ }^{4}$, Margherita Ferrante ${ }^{1}$
}

${ }^{1}$ Department G.F. Ingrassia-Hygiene and Public Health, University of Catania, Catania, Italy; ${ }^{2}$ Department of Public Health, University of Parma, Parma, Italy; ${ }^{3}$ Department of Surgery, Medicine, Odontoiatrics and Morphological Sciences, University of Modena and Reggio Emilia, Modena, Italy; ${ }^{4}$ Department of Diagnostic and Clinical Medicine and of Public Health, University of Modena and Reggio Emilia, Modena, Italy.

Email: ${ }^{*}$ olivericonti@unict.it

Received March $18^{\text {th }}, 2013$; revised April 19 ${ }^{\text {th }}, 2013$; accepted April $29^{\text {th }}, 2013$

Copyright (C) 2013 Chiara Copat et al. This is an open access article distributed under the Creative Commons Attribution License, which permits unrestricted use, distribution, and reproduction in any medium, provided the original work is properly cited.

\begin{abstract}
Fish is a very important food because of its high nutritional value. Fish consumption is largely recommended in all countries, so quality and safety of seafood are becoming of great concern. Especially in Mediterranean Sea, where many pollutants, as metals and Polycyclic Aromatic Hydrocarbons (PAHs), are often relieved also in high concentrations, seafood safety has to be checked by a methodologically rigorous risk assessment. So we propose in this paper a stagesrisk assessment methodology to estimate the seafood potential risk for human health and point-out critical topics in order to support fish advisories.
\end{abstract}

Keywords: Risk Assessment; Seafood Safety; Contamination; Sea Environment; Metals; Polycyclic Aromatic Hydrocarbons

\section{Introduction}

Fish is a very important food because its high nutritional value [1-3] and his consumption is largely recommended in all countries [4,5]. Thus, safety of seafood is becoming of great concern, to better characterize balance between benefits and risks due to ingestion of chemical contaminants [6].

Toxic chemicals released to the environment from point sources such as industrial and municipal discharges and from nonpoint sources such as agricultural runoff and atmospheric deposition have contaminated surface waters and their sediments across [7].

Many chemical pollutants are concentrated in fish and shellfish by accumulating in fatty tissues or selectively binding to fish muscle tissue (the fillet) in relation to waterborne and dietary exposure [8-11]. Even extremely low concentrations of bioaccumulative pollutants detected in water or bottom sediments may result in marine plants [12], fish or shellfish tissue concentrations high enough to pose health risks to fish consumers. Lipophilic contaminants, particularly certain organochlorine com-

"Corresponding author. pounds, tend to accumulate in the fatty tissues of fish. Consequently, fish species with a higher fat content, such as carp, bluefish, some species of salmon, and catfish, may pose greater risks from some contaminants than leaner fish such as bass, sunfish, and yellow perch. Although exposure to some contaminants may be reduced by removing the fat, skin, and viscera before the fish is eaten, other contaminants, such as methylmercury, are accumulated in the muscle tissue of the fillet and therefore cannot be removed by trimming. In addition, some fish are consumed whole or are used whole in the preparation of fish stock for soups and other foods. Under these conditions, the entire body burden of bioaccumulative contaminants contained in the fish would be ingested by the consumer [13].

Mediterranean Sea has limited water exchange with the open seas, and many pollutants, such as metals and polycyclic aromatic hydrocarbons (PAHs), are often relieved also in high concentrations for the combined effect of anthropic and natural origin, the last caused by submarine volcanic emission characteristic of the area $[14,15]$.

Thus, this sea is thus sensitive to the build-up of pollutants that may cause a progressive degradation of the 
marine ecosystem [16,17] and seafood safety has to be checked by a methodologically rigorous risk assessment.

So we propose in this paper a stages-risk assessment methodology to estimate the potential and real risk for human health derived from seafood consumption in order to support fish advisories.

\section{Materials and Methods}

For risk assessment to estimate the potential and real risk for human health derived from seafood consumption first of all, it must been identify specific chronic and acute health effects of the metals and PAHs chosen for the risk assessment, proceeding with performing the extraction of the selected contaminants from fish and shellfish tissues.

To date, according with the most appropriate technique in use, metals analysis must be carried on by ICPMS technique coupled with an LC pump for the element speciation, and for PAHs by HPLC-UV/FL or GC-MS. Samples must be processed together with a certified reference material to validate the analysis. Alternatively, it should be spiked real samples to check the recovery for each contaminant.

Furthermore, after dosage of pollutants, evaluates means

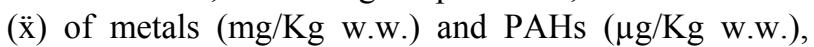
standard deviation (SD) and analysis of variance with almost the minimum level of significance fixed at $p<0.05$.

For the risk assessment it must be applied Environmental Protection Agency methodology [16-19] settled to standardize advisory consumption recommendations for minimizing the risk of both cancer and non-cancer endpoints due to the consumption of fish.

For the potential risk assessment, all consumption rate and risk factors should be calculated assumed for adults an ingestion rate of $227 \mathrm{~g}$ (meal size) and a body weight $(B W)$ of $70 \mathrm{Kg}$ [19], and for child of six years old a ingestion rate of $114 \mathrm{~g}$ and a $B W$ of $16 \mathrm{Kg}$ [20].

For the real risk assessment, a validate questionnaires should be provided to local population to obtain real data on the seafood consumption frequency, the ingestion rate (substitutive of the assumed meal size), the body weight and the age classes.

Additionally, based on the US-EPA guidance [21], we assume that the ingestion dose is equal to the adsorbed contaminant dose and that cooking has no effect on the contaminants [22].

For a preliminary investigation, the estimated daily intake $(E D I)$ according to the equation reported in previous reports $[8,9]$ should be calculated:

$$
E D I=(I R \times C) / B W
$$

where $I R$ is the ingestion rate daily or meal size, $C$ is the metal concentratio (mg/kg w.w.); $B W$ is the body weight.

All consumption rates after calculation can be compared with daily and weekly tolerable intake (TI) levels suggested by the World Health Organization for specific contaminants. If no speciation was carried out Food and Drug Administration (FDA) gives values in \% for inorganic and organic forms of metals.

According to the guideline of the United State Environmental Protection Agency [21] and based on the USEPA guidance [16], it is possible proceeding to calculate other risk factors.

Target Hazard Quotient (THQ), indicate the ratio between exposure and the reference dose, and calculations have to be made using the standard assumption for an integrate US-EPA risk analysis.

$$
T H Q=(E F \times E D \times I R \times C) /(R f D o \times B W \times A T)
$$

$E F$ is the exposure frequency (350 days/year for people that eat fish 7 times a week); $E D$ is the exposure duration (adults, 70 years; child, 6 years); IR is the food ingestion rate; $C$ is the metal concentration in fish $(\mu \mathrm{g} / \mathrm{g}$, wet weight); RfDo is the oral reference dose $(\mu \mathrm{g} / \mathrm{g} /$ day $) ; B W$ is the body weight; $A T$ is the averaging time (it is equal to $E F \times E D$ ). If $T H Q$ risk is above 1 , value considered by the US-EPA, it is assumed as an acceptable risk for chronic systemic effects.

Then Incremental lifetime cancer risk (ILCR) for estimate the potential carcinogen risk associated with exposure at measured dose of pollutant must be obtained by using the Cancer Slope Factor (CSF) or Unit Risk in the following equation [18]:

$$
I L C R=(E F \times E D \times I R \times C \times C S F) /(B W \times A T)
$$

where CSF is the daily dose ( $\mu \mathrm{g} / \mathrm{g} /$ day) set by US-EPA only for inorganic As. If ILCR risk is above the $10^{-5}$ value considered by the US-EPA, it is assumed as an acceptable risk for cancer and the risk assessment should either be refined and/or risk management measures should be taken.

As suggested by US-EPA, the allowable number of fish meals of a specific meal size that may be consumed oven a given period of time should be also evaluated.

For carcinogenic effects, US-EPA provides the equation to calculate maximum allowable fish consumption rate $(C R m w c)$ meals/week expected to generate a risk no greater than the maximum acceptable individual lifetime risk $(A R L)$, considered to be 1 in 100,000 for almost studies.

Firstly it must be calculated the allowable daily consumption $(C R d c)$ of contaminated fish, that represents the amount of fish (in kilograms) expected to generate a risk no greater than the maximum $A R L$ used.

$$
C R d c=\frac{A R L \times B W}{C S F \times C m}
$$

To calculate weekly fish meal consumption limits, the previous equation is modified as follows: 


$$
C R m w c=\frac{C R d c \times T a p}{M S}
$$

where $M S$ is the daily ingestion rate or meal size and Tap is the time averaging period ( 7 days/week).

For non-carcinogenic effects, the maximum allowable fish consumption rate (CRmmr) meals/week that would not be expected to cause adverse non-carcinogenic health effects, is also provided by US-EPA.

Firstly it must be calculated the maximum lifetime daily consumption rate (CRdr) (in kilograms of fish) that would not be expected to cause adverse non-carcinogenic health effects

$$
C R d r=\frac{R f D o \times B W}{C m}
$$

Then, the CRdr equation is modified as the previous for the calculations of consumption rate meal/week (CRmwr).

\section{Discussion and Conclusions}

Supporting a unique guide for the risk assessment resulting from consumption of contaminated seafood is basilar for a common risk prevention and management plan.

Toxicity of some metals and PAHs is known, but, to date, there isn't regulatory limit for all hazard substance in food. For example, the European Regulation 1881/ 2006 [23] sets a threshold only for $\mathrm{Cd}, \mathrm{Pb}, \mathrm{Hg}$, and benzo (A) pyrene, but the World Health Organizations, the Environmental Protection Agency and others international organizations have suggested tolerable ingestion rates such as tolerable intake, reference dose and cancer slope factor applicable to a large numbers of pollutants. The Evaluations of the Joint FAO/WHO Expert Committee on Food Additives (JECFA) online database and the EPA's Integrate Risk Information System (IRIS) provide the above mentioned doses. For a comprehensive risk assessment of fish intake, also other elements such as the metalloid selenium, which is of both nutritional and toxicological interest and whose safe range of intake has still not been clearly defined [24], should be considered.

Most RfDo are based on chronic exposure studies. Because the contaminant concentrations required to produce chronic health effects are generally lower than those causing acute health effects, the use of chronic RfDo in developing consumption limits is expected to also protect consumers against acute health effects. CSFs are instead based on carcinogenic exposure studies.

Regarding consumption limits for PAHs, EPA's Integrated Risk Information System (IRIS) provides information on a cancer slope factor only for benzo (A) pyrene, which is considered as probable human carcinogen (group B2) based on sufficient evidence of carcinogenicity in animals. Furthermore, EPA considers that total PAHs have the same cancer slope factor as BaP.
Among metals, only as have a settled CSF. Although the role of As is not clear, it has been proposed that the As mediated intracellular biosynthesis of reactive oxygen species (ROS) such as free radicals (particularly $\mathrm{H}_{2} \mathrm{O}_{2}$ ), may be implied in the carcinogenic process induced by As via DNA damage [25,26]. Many studies support the correlation between inorganic as exposure and cancer in the skin, lung, bladder or kidney [25-30].

For a valid risk assessment is very important to obtain more laboratory results, such as in vivo exposure to pollutants and environmental monitoring, in quality to obtain further data and applied validate risk factors equations to a larger number of contaminants.

Thus, this investigated issue should be studied further in the future, to get missing data on cancer slope factor as well as on reference doses and a better comprehension of seafood safety.

\section{REFERENCES}

[1] E. I. Adeyeye, "Determination of the Chemical Composition of the Nutritionally Valuable Parts of Male and Female Common West African Fresh Water Crab Sudananautes africanus africanus," International Journal of Food Sciences and Nutrition, Vol. 53, No. 3, 2002, pp. 189-196. doi:10.1080/09637480220132805

[2] P. A. Zalloua, Y. H. Hsu, H. Terwedow, T. Zang, D. Wu, G. Tang, Z. Li, X. Hong, S. T. Azar, B. Wang, M. L. Bouxsein, J. Brain, S. R. Cummings, C. J. Rosen and X. $\mathrm{Xu}$, "Impact of Seafood and Fruit Consumption on Bone Mineral Density," Maturitas, Vol. 56, No. 1, 2007, pp. 1-11. doi:10.1016/i.maturitas.2006.05.001

[3] B. Ersoy and M. Celik, "The Essential and Toxic Elements in Tissues of Six Commercial Demersal Fish from Eastern Mediterranean Sea," Food and Chemical Toxicology, Vol. 48, No. 5, 2010, pp. 1377-1382. doi:10.1016/j.fct.2010.03.004

[4] B. Olang, M. Hajifaraji, M. A. Ali, S. Hellstrand, M. Palesh, E. Azadnyia, Z. Kamali, B. Strandvik and A. Yngve, "Docosahexaenoic Acid in Breast Milk Reflects Maternal Fish Intake in Iranian Mothers," Food and Nutrition Sciences, Vol. 3, No. 4, 2012, pp. 441-446.

[5] E. P. Neale, A. Cossey, Y. C. Probst, M. J. Batterham and L. C. Tapsell, "Effectiveness of Dietary Advice to Increase Fish Consumption over a 12-Month Period," Food and Nutrition Sciences, Vol. 3, No. 4, 2012, pp. 455-460. doi:10.4236/fns.2012.34065

[6] J. L. Domingo, A. Bocio, G. Falco and J. M. Llobet, "Benefits and Risks of Fish Consumption Part I. A Quantitative Analysis of the Intake of Omega-3 Fatty Acids and Chemical Contaminants," Toxicol, Vol. 230, No. 2-3, 2007, pp. 219-226. doi:10.1016/j.tox.2006.11.054

[7] G. Longo, M. Trovato, V. Mazzei, M. Ferrante and G. Oliveri Conti, "Ligia italica (Isopoda, Oniscidea) as Bioindicator of Mercury Pollution of Marine Rocky Coasts," PLoS One, Vol. 8, No. 3, 2013, Article ID: e58548. doi:10.1371/journal.pone.0058548

[8] G. O. Conti, C. Copat, C. Ledda, M. Fiore, R. Fallico, S. 
Sciacca and M. Ferrante, "Evaluation of Heavy Metals and Polycyclic Aromatic Hydrocarbons (PAHs) in Mullus barbatus from Sicily Channel and Risk-Based Consumption Limits," Bulletin of Environmental Contamination and Toxicology, Vol. 88, No. 6, 2012, pp. 946-950. doi:10.1007/s00128-012-0611-1

[9] C. Copat, F. Bella, M. Castaing, R. Fallico, S. Sciacca and M. Ferrante, "Heavy Metals Concentrations in Fish from Sicily (Mediterranean Sea) and Evaluation of Possible Health Risks to Consumers," Bulletin of Environmental Contamination and Toxicology, Vol. 88, No. 1, 2012, pp. 78-83. doi:10.1007/s00128-011-0433-6

[10] C. Copat, M. V. Brundo, G. Arena, A. Grasso, G. Oliveri Conti, C. Ledda, R. Fallico, S. Sciacca and M. Ferrante, "Seasonal Variation of Bioaccumulation in Engraulis encrasicolus (Linneaus, 1758) and Related Biomarkers of Exposure," Ecotoxicology and Environmental Safety, Vol. 86, 2012, pp. 31-37. doi:10.1016/j.ecoenv.2012.09.006

[11] B. Tomasello, C. Copat, V. Pulvirenti, V. Ferrito, M. Ferrante, M. Renis, S. Sciacca and C. Tigano, "Biochemical and Bioaccumulation Approaches for Investigating Marine Pollution Using Mediterranean Rainbow Wrasse, Coris julis (Linneaus 1798)," Ecotoxicology and Environmental Safety, Vol. 86, 2012, pp. 168-175. doi:10.1016/j.ecoenv.2012.09.012

[12] C. Copat, R. Maggiore, G. Arena, S. Lanzafame, R. Fallico, S. Sciacca and M. Ferrante, "Evaluation of a Temporal Trend Heavy Metals Contamination in Posidonia oceanica (L.) Delile, (1813) along the Western Coastline of Sicily (Italy)," Journal of Environmental Monitoring, Vol. 14, No. 1, 2012, pp. 187-192.

doi: $10.1039 / \mathrm{c} 1 \mathrm{em} 10575 \mathrm{~b}$

[13] US-EPA, "Guidance for Assessing Chemical Contamination Data for Use in Fish Advisories Volume II. Risk Assessment and Fish Consumption Limits EPA/823-B94004," United States Environmental Protection Agency, Washington DC, 2000.

http://www.epa.gov/spc/pdfs/rchandbk.pdf

[14] R. Ferrara, B. Mazzolai, E. Lanzillotta, E. Nucaro and N. Pirrone, "Volcanoes as Emission Sources of Atmospheric Mercury in the Mediterranean Basin," Science of the Total Environment, Vol. 259, No. 1-3, 2000, pp. 115-121. doi:10.1016/S0048-9697(00)00558-1

[15] R. Di Leonardo, G. Tranchida, A. Bellanca, R. Neri, M. Angelone and S. Mazzola, "Mercury Levels in Sediments of Central Mediterranean Sea: A 150+ Year Record from Box-Cores Recovered in the Strait of Sicily," Chemosphere, Vol. 65, No. 11, 2006, pp. 2366-2376. doi:10.1016/j.chemosphere.2006.04.076

[16] US-EPA, "Risk Assessment Guidance for Superfund Volume I. Human Health Evaluation Manual (Part A)", Interim Final. EPA 540/1-89/002," United States Environmental Protection Agency, Washington DC, 1989. http://www.epa.gov/spc/pdfs/rchandbk.pdf

[17] UNEP, "Mediterranean Regional Report. Regionally Based Assessment of Persistent Toxic Substances," 1996. http://www.chem.unep.ch/

[18] US-EPA, "Exposure Factors Handbook," National Center for Environmental Assessment, Washington DC, 1997. http://www.epa.gov/spc/pdfs/rchandbk.pdf
[19] US-EPA, "Risk-Based Concentration Table," United States Environmental Protection Agency, Philadelphia, 2000. http://www.epa.gov/spc/pdfs/rchandbk.pdf

[20] I. Mansilla-Rivera and C. J. Rodriguez-Sierra, "Metal Levels in Fish Captured in Puerto Rico and Estimation of Risk from Fish Consumption," Archives of Environmental Contamination and Toxicology, Vol. 60, No. 1, 2011, pp. 132-144.

[21] US-EPA, "Risk Characterization Handbook," US Environmental Protection Agency, Washington DC, 2000. http://www.epa.gov/spc/pdfs/rchandbk.pdf

[22] L. C. Chien, T. C. Hung, K. Y. Choang, C. Y. Yeh, P. J. Meng, M. J. Shieh and B. C. Ha, "Daily Intake of TBT, $\mathrm{Cu}, \mathrm{Zn}, \mathrm{Cd}$ and As for Fishermen in Taiwan," Science of the Total Environment, Vol. 285, No. 1-3, 2002, pp. 177185. doi:10.1016/S0048-9697(01)00916-0

[23] EC. Commission Regulation N. 1881/2006, "Setting Maximum Levels of Certain Contaminants in Foodstuff," Official Journal of the European Union, Legislation Series, Vol. 65, 2006, pp. 5-24.

[24] M. Vinceti, T. Maraldi, M. Bergomi and C. Malagoli. "Risk of Chronic Low-Dose Selenium Overexposure in Humans: Insights from Epidemiology and Biochemistry," Reviews on Environmental Health, Vol. 24, No. 3, 2009, pp. 231-248. doi:10.1515/REVEH.2009.24.3.231

[25] NRC, "Commitee on Toxicology. Arsenic in Drinking Water," The National Academic Press, Washinton DC, 2001.

http://www7.nationalacademies.org/ocga/testimony/arseni c_in_drinking_water.asp

[26] V. Sirot, T. Guerin, J. L. Volatier and J. C. Leblanc, "Dietary Exposure and Biomarkers of Arsenic in Consumers of Fish and Shellfish from France," Science of the Total Environment, Vol. 407, No. 6, 2009, pp. 1875-1885. doi:10.1016/j.scitotenv.2008.11.050

[27] M. M. Wu, T. L. Kuo, Y. H. Hwang and C. J. Chen. "Dose-Response Relation between Arsenic Concentration in Well Water and Mortality from Cancers and Vascular Diseases," American Journal of Epidemiology, Vol. 130, No. 6, 1989, pp. 1123-1132.

[28] C. J. Chen, C. W. Chen, M. M. Wu and T. L. Kuo, "Cancer Potential in Liver, Lung, Bladder and Kidney Due to Ingested Inorganic Arsenic in Drinking Water," British Journal of Cancer, Vol. 66, No. 5, 1992, pp. 888-892. doi: $10.1038 /$ bjc. 1992.380

[29] A. H. Smith, C. Hopenhayn-Rich, M. N. Bates, H. M. Goeden, I. Hertz-Picciotto, H. M. Duggan, R. Wood, M. J. Kosnett and M. T. Smith, "Cancer Risks from Arsenic in Drinking Water," Environmental Health Perspectives, Vol. 97, 1992, pp. 259-267. doi:10.1289/ehp.9297259

[30] C. O. Abernathy, Y. P. Liu, D. Longfellow, H. V. Aposhian, B. Beck, B. Fowler, R. Goyer, R. Menzer, T. Rossman, C. Thompson and M. Waalkes, "Arsenic: Health Effects, Mechanisms of Actions, and Research Issues," Environmental Health Perspectives, Vol. 107, No. 7, 1999, pp. 593-597.

http://www.ncbi.nlm.nih.gov/pmc/articles/PMC1566656/ doi:10.1289/ehp.99107593 